\title{
SOME BOOKS OF 1964
}

$\mathrm{O}$ UR theme this month is mental health books. We have tried both to cover as many publications as possible, and to give space to our reviewers for detailed accounts of some important books. This is something that needs to be done, because the output of work in the scientific and social fields has become immense. Means of communication are more effective, but quantity threatens to overwhelm the individual, or even the team, since there is no new way of taking in and considering all this material. But something of this sort must happen before long, and there is an indication of how it might be done in the Mental Health Book Review Index.

Volume Nine of this series has just been published by the Research Centre for Mental Health in New York. This covers some 200 professional journals throughout the world, and shows the clusters of interest that form around certain books which are reviewed in them. Bibliography is used here to study trends in the mental health literature, and to find out what is going on in this sector of the scientific community. Other studies of this sort will probably provide some guiding lights in the future.

\section{Common language}

It is also useful to find a book which draws many threads together. Systems of Psychotherapy, by Donald H. Ford and Hugh B. Urban (Wiley, 83s.), is a critical but sympathetic review of ten different theories and treatment approaches, which are varying forms of psychotherapy. It is rightly claimed to be unique in reducing all these very diverse systems to a common language. From this, one can see clearly how each theory is actually related to the treatment methods which are used to implement it. It is also unique in considering behaviour-therapy alongside the various schools derived from psychoanalysis without indulging in any of the usual mud-slinging. There has been a good deal of demand for "scientific" study of psychotherapy, and indeed our experimental methods here are still in their infancy. This book has no new laboratory or clinical studies, but it is "scientific" in the best sense of the word-forsaking jargon and allowing theories to be analysed in objective terms. Most professional workers involved in mental health will find this very useful.

One cannot really say the same of the next book (Group Therapy: $A$ Practical Approach, by James A. Johnson, McGraw Hill, 85s.). One of our reviewers has referred before to the enormous amount of writing this subject has aroused-a quantity rather out of proportion to the number of patients treated. Much of it, including the present book, is firmly rested in psychoanalytical theory, rather to the neglect of clinical psychiatry and of other theoretical systems which are relevant to groups. Almost half these 467 pages are taken up with a detailed account of the meetings of an out-patient group which went on for 19 months. The material here contains much of interest, though the writing is tedious at times, as it is in the theoretical sections. The book ends with chapters on group therapy with psychotic patients and on hospital ward meetings. Those with a special interest in group work will not wish to overlook it.

\section{Original writing}

From a rather over-written field it is refreshing to move on to something which is original. Stress and Release in an Urban Estate, by John Spencer et al. (Tavistock, 45s.), is an account of the Bristol Social Project, which grew out of concern of various citizen groups with delinquency and other 
social problems. The project offered belp to adolescents, inadequate mothers, toddlers and difficult children, with seminars for teachers and social workers. The problems tackled Were those thrown up by the community itself, and it was hoped that the intervention of the project-team would have a long-term effect, through its influence on the people involved. The method was "action-research", which was regarded as being significantly different from both research and social Work in the usual senses. As in the previous book, it is the practical account of what was done which will be of most interest and value. This is the first of two volumes, so that it should presumably not be judged on its OWn, but whilst one is filled with admiration for the professional workers concerned, the theoretical background raises some awkward questions. Nevertheless, it will be essential reading for anyone involved with the various social problem groups which this Project tried to help.

A surprisingly neglected field in the literature up to now (and one much more in public and professional awareness) is that of sexual problems. The Pathology and Treatment of Sexual Deviation, edited by Ismond Rosen (Oxford University Press, 50s.), is the most comprehensive work of its kind to appear in this country. The biological and cultural background to perversions is particularly well covered by distinguishd contributors such as Tinbergen and Carstairs, and the psychoanalytical view is strongly represented. It is perhaps a pity that the behavioural approach is described by someone who is highly critical of it, since the reader might have been left to decide this more for himself. But this book is obviously going to be indispensable to everyone who is professionally concerned with sexual deviation. On a different level, but at least as admirable, is Dr. Anthony Storr's Sexual Deviation (Penguin, 3s. 6d.). This is a most important contribution to public education, and its humane and sensible approach can do nothing but good. Although it is written for the layman, most professional workers would gain from reading it-both to clarify their own ideas, and to help them explain these problems to the public.

Finally, Professor Peter Townsend's important survey of homes for the aged (The Last Refuge, Routledge, 30s.) has been issued in a usefully abridged form, leaving out the statistical tables. This is one of the most significant pieces of social research carried out in this country in recent years, and the photographs of ex-workhouse accommodation are unforgettable. Unfortunately, there is little evidence of real progress in the two years since it was first written, as far as the care of the aged is concerned.

As we mentioned last June, this is the last edition of Mental Health to include the General Secretary's Letter and local associations article, which will now form a separate news-sheet. It it hoped that at least some of the extra space in each of our forthcoming issues will be devoted to more reviews of mental health books.

\section{LOPPINGTON HOUSE WEM, SHREWSBURY, SHROPSHIRE}

Helpless children from birth to 12 years, no matter how severely handicapped, are accepted for long- or short-term care by Mrs. Harvey at Loppington House.

A Registered Mental

Details on Nursing Home.

Application

Telephone: Loppington 665 